\section{Military Technical College Kobry El-Kobbah, Cairo, Egypt}

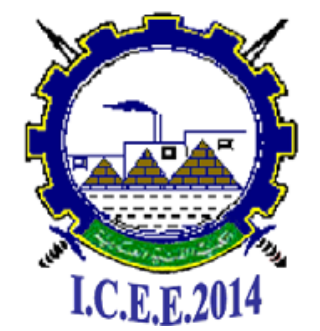

CEED-1 $7^{\text {th }}$ International Conference

on

Chemical \& Environmental Engineering

27 - 29 May, 2014.

\title{
Oxidative Stress and Chronic Exposure To Low Levels of Benzene
}

\author{
Kotb MA ${ }^{* \dagger}$, Ramadan $\mathrm{HS}^{\dagger}$, Siam ME$^{\ddagger}$, El-Bassiouni EA. ${ }^{\S}$
}

\begin{abstract}
Benzene is found in the environment as a contaminant from both human activities and natural processes posing serious bio-hazards from chronic exposure. To study the health hazards from chronic exposure to low levels of benzene, an all-male cohort of 390 individuals were recruited. This cohort study included 75 healthy individuals that served as a control group and 315 individuals occupationally chronically exposed to low-levels of benzene in their daily activity during routine work in some petroleum industries.
\end{abstract}

Benzene itself was not detected in the blood or urine of all participants, but the levels of its metabolites; phenol and muconic acid were higher in the blood and urine samples of the group of benzene-exposed workers. Inspection of the results of the study clearly shows that the benzene-exposed workers are under oxidative stress, as judged by higher malondialdehyde, the end product of lipid peroxidation, and lower total antioxidant defense in the blood of exposed workers. This was confirmed by lowered total and reduced glutathione and elevated oxidized form. The effect on cellular membranes was reflected in increased breakage of red blood cells (RBCs) membranes causing higher degree of hemolysis.

The data indicate, that chronic exposure to benzene, even at low variable levels, causes biochemical and biophysical alterations that are detrimental to the health and well-being of exposed workers.

\section{Key words:}

Benzene, Glutathione, Muconic acid, Phenol, Malondialdehyde, Redox potential.

\footnotetext{
*† Dept. of Medical- Biophysics, Medical Research Institute, Alexandria University.

$\dagger \quad$ Dept. of Medical- Biophysics, Medical Research Institute, Alexandria University.

$\ddagger$ Research laboratory, Chemistry administration, Ministry of industry and foreign trade Alexandria, Egypt .

$\S \quad$ Dept. of Pharmacology, Medical Research Institute, Alexandria University, Egypt.
} 


\section{Introduction}

As a component of petroleum products [1, 2], including gasoline, and as an impurity in many industrial products, benzene results in continued occupational exposure, especially in small, uncontrolled workshops [3]. The reported biochemical and hematological data indicate that exposure, even to low variable levels of benzene, may lead to health problems [4].

Benzene enters the body mainly through inhalation of contaminated air or through contact with the skin [5]. Following absorption, benzene is distributed throughout the body. Its residence time in blood varies depending on the duration and magnitude of exposure [6, 7]. Pharmacokinetics of benzene in humans appears to follow a two-compartment model with a half-life of distribution of about one hour and that of elimination of 24 hours [8]. Elimination takes place mainly either through exhalation of unchanged benzene or through metabolism. The main metabolites excreted in the urine; phenol and t,t, muconic acid, Sphenylmercapturic acid may be used as biomarkers to estimate the extent of exposure and possible health risk [3, 9]. It has been proposed that workers in benzene-contaminated environment are under oxidative stress, which may predispose them to occupational diseases [4]. However, full assessment of the degree of oxidative stress status was not reported.

The present work was undertaken to further assess the degree of oxidative stress and evaluate the level of the half cell redox potential in order to get a better idea about the probable deleterious effects of low, although variable, levels of benzene on the health of exposed workers.

\section{Subjects and Methods}

Seventy-five healthy individuals (age range 25 to 58 years) forming a control group and three hundred and fifteen individuals (age range 23 to 60 years) occupationally chronically exposed to low-levels of benzene in their daily work, participated in the present study. This cohort was recruited from the city of Alexandria. The conditions of their work environment and working times were recorded and the level of benzene in ambient air was measured ${ }^{[10]}$. All participants were of the same socio-economic standard with similar living conditions and dietary habits. Exclusion criteria from the study included individuals with endocrine problems, like diabetes mellitus or thyroid dysfunction. The ethics committee of the Medical Research Institute, of Alexandria University, approved the study protocol and all procedures were done according to the Helsinki Declaration of 1975, as revised in 1983.

After explaining the objectives of the study, each subject signed a written informed consent and a $5 \mathrm{ml}$ blood sample was withdrawn over EDTA, by qualified personnel under complete aseptic conditions. A spot urine sample was also obtained. All samples were kept in sealed containers for further analysis. The degree of hemolysis in the blood samples was immediately measured [11]. Benzene and its metabolites; phenol and trans, transmuconic acid were assayed in blood and urine by a high performance liquid chromatographic technique [12, 13]. Urinary creatinine level was determined by autoanalyzer and used to normalize the concentrations of both phenol and t,t, muconic acid in urine as adopted by NIOSH.

Different parameters of oxidative stress were assessed. The level of malondialdehyde (MDA), was estimated by a colorimetric method (Bio diagnostic, Egypt) as a measure of lipid peroxidation $[14,15]$. The levels of total glutathione, as well as the reduced and oxidized forms were determined [16] and the redox potential was calculated using the equation [17]: 


\section{Redox potential $=-240-(59.1 / 2) \log \left([G S H]^{2} /[G S S G]\right) \mathrm{mV}$.}

The total antioxidant activity in plasma was assessed by a ready-for-use kit (Bio diagnostic, Egypt). The assay method depended on the elimination of a defined amount of exogenously added hydrogen peroxide by the antioxidants in the sample followed by colorimetric determination of the excess hydrogen peroxide present.

[N.B.]: GSH: Glutathione (reduced form).

: GSSG: Glutathione disulfide (oxidized form).

: NIOSH: National Institute for Occupational Safety and Health.

: Redox Potential: Reduction Potential (Oxidation/Reduction Potential\}.

All values were analyzed by Statistical Package for Social Science (SPSS) version 10. Paired t-test was used to compare two mean parameter values and the level of significance was set at $P$ value of 0.05 or less.

\section{Results:}

The benzene concentration in ambient air ranged from 4.96 to $260.86 \mathrm{ng} / \mathrm{L}$ (mean 97.56 $+88.12 \mathrm{ng} / \mathrm{L}$ ) as measured by the electronic nose technique [10]. The relatively higher levels were found in printing shops where subjects worked in confined areas. The levels of benzene in air varied with the location of the workplace and its proximity to the seashore, where there was better aeration.

The results of the concentration of the main metabolites of benzene are presented in Table 1. Benzene itself was not detected either in the urine or in the plasma of all subjects tested. Muconic acid was also undetectable in the plasma of control subjects, but present in their urine samples at a low average level of $0.07 \pm 0.02 \mathrm{mg} / \mathrm{g}$ creatinine. However, muconic acid was detected in the plasma and urine of exposed workers, with highly variable concentrations. On the other hand, phenol, the second assayed benzene metabolite, was present in all blood and urine Samples, with higher concentrations in samples from exposed workers. The mean phenol level in the blood of exposed workers averaged $73 \%$ above mean control value and was $80 \%$ higher in the urine.

Workers exposed to low levels of benzene were found to be under oxidative stress (Table 2). There were significant elevations of plasma MDA levels, and decrease in plasma total antioxidant activity as compared to control values. The average MDA level was $57.4 \%$ higher in the exposed group where its value was $1.81 \pm 1.51 \mathrm{mmol} / \mathrm{L}$ as compared to $1.15 \pm$ $1.04 \mathrm{mmol} / \mathrm{L}$ for controls, while the mean plasma total antioxidant capacity $(0.83+0.55$ $\mathrm{mmol} / \mathrm{L})$ was $45 \%$ lower than the corresponding control values $(1.51 \pm 0.51 \mathrm{mmol} / \mathrm{L})$. The results of glutathione assays confirmed the presence of oxidative stress and lower degree of antioxidant defense. Both mean levels of total and reduced glutathione were significantly lower in benzene exposed workers, while oxidized glutathione was more than $20 \%$ higher than mean control value. The calculated redox potential was also indicative of the decreased reductive capabilities of the blood, as it changed from $-116.03 \pm 8.86 \mathrm{mV}$ in controls to $108.45 \pm 3.51 \mathrm{mV}$ in benzene exposed workers.

A higher degree of hemolysis was observed in the blood samples from benzene-exposed individuals. While the degree of hemolysis ranged between zero and $2 \%$ (mean $1.4 \%$ ) in control samples, it averaged about 5.2\% in the exposed individuals, reaching values as high as 9 to10\% in some cases. 


\section{Discussion}

Moderate and long-term exposures of humans to benzene may cause numerous untoward effects. The most serious health hazards in these cases appear to be of hematologic, immunologic, genetic and malignant natures [18-21]. The widespread pollution by benzene was

[N.B.]: ng/L : Nanogram per Litre.

: mmol/L: millimoles/ Litre.

$: \mathrm{mg} / \mathrm{g} \quad$ : milligram per gram.

$: \mathrm{mV} \quad$ : millivolts.

evident by the presence of its metabolite; phenol, in the blood and urine of control individuals.

The inability to detect benzene itself in the blood or urine of workers exposed to low levels of ambient air may be attributed to many reasons including: (i) the levels were below the detection limits of the assay method, (ii) rapid distribution into adipose tissues, especially since animal data indicate that benzene distributes rapidly and preferentially to adipose tissues $[22,23]$ and, (iii) slow redistribution from adipose tissues back into the blood with rapid oxidation, mainly by liver enzymes. The blood levels of the benzene metabolites; phenol and muconic acid, were higher in the group of benzene-exposed workers. This probably is indicative of the higher rate of contact with benzene-contaminated environment and consequently increased possibility of deleterious consequences of such exposure. The presence of benzene metabolites in the blood and urine of control individuals probably resulted from incidental exposure, and accordingly reflect the level of air pollution by car exhaust and other contaminants in the city. The high variability of the concentrations of metabolites in blood and urine may be due to variations in both the level of pollution and duration of exposure or genetic polymorphism in the metabolism of benzene. This last possibility, which is currently under investigation, may affect the type and level of the metabolites and consequently the health hazards caused by chronic exposure to benzene.

The results of the present study clearly indicate that the benzene-exposed workers are under oxidative stress as shown by elevated blood levels of MDA with elevated and depressed total antioxidant activity.

Malondialdehyde is the principal product derived from lipid peroxidation, but it can also be generated by enzymatic processes from metabolism of various prostaglandins [24]. However, MDA should not be considered only as a simple marker for lipid peroxidation, but a clear alarm of high risk of mutation. In its physiological state, at neutral $\mathrm{pH}$, MDA is of low chemical reactivity [25], but it is able to interact with nucleic acid bases to form several different adducts [26]. The main product of this reaction is able to induce sequence-dependent frame shift mutations and base-pair substitutions in different cell types ${ }^{[25]}$. MDA is also able to generate DNA-protein (e.g., histones) cross links under physiological conditions [26].

Oxidative stress was also confirmed by the results of the glutathione blood levels, which clearly showed a decrease in total and reduced glutathione with increased oxidized form. The main protective roles of glutathione against oxidative stress are: [i] glutathione is a cofactor for other detoxifying enzymes like glutathione peroxidase (GPx), and glutathione transferase [ii] GSH participates in amino acid transport through the plasma membrane; [iii] GSH scavenges hydroxyl radicals and singlet oxygen directly, detoxifying hydrogen peroxide and 
lipid peroxides by the catalytic action of glutathione peroxidase; [iv] Glutathione is able to reduce oxidized vitamin $\mathrm{C}$ and vitamin $\mathrm{E}$ back to their unoxidized state. Moreover, GSH in the nucleus is involved in mechanisms that are necessary for DNA repair and expression [27].

The reductive capability in the blood was also affected as indicated by the change in the redox potential toward a more oxidative environment. Such condition causes cellular damage that is implicated in many chronic diseases such as diabetes mellitus and cancer among many others [28-31], and may predispose exposed workers to occupational diseases.

The effect of exposure to benzene on cellular membranes was represented by the integrity of the membrane of the RBC. Either benzene itself, as an organic solvent, or more probably the increased oxidative stress in the blood of exposed workers affecting the integrity of the lipoid membrane. This was reflected in weaker membrane and increased tendency toward hemolysis. This should be considered in the overall changes in the biophysical characteristics of the blood of benzene-exposed individuals, which indicate alterations in such properties as increased RBCs aggregation leading to higher blood viscosity [4]. This is particularly important in microcirculation as it affects hemodynamics [32].

The accumulated data indicate that chronic exposure to benzene, even at low variable levels, cause biochemical and biophysical alterations that are detrimental to the health and well-being of exposed workers. It is probable that the oxidative stress and the changes in hemodynamic properties may hinder the cognitive functions and ability to acquire skills in children and young adolescents working in environments polluted with benzene. This would affect the quality of their lives and the development of their careers.

\section{Acknowledgement}

This work was supported in part by Grant ID: 963 from the Science and Technology Development Fund, Egyptian Ministry of Scientific Research.

The authors would like to extend their special thanks to Mrs. Mahrvan Ragab, Senior contracting and Technical follow-up, Science \& Technology Development Fund (STDF), and her staff for their help and co-operation throughout the course of the present study.

\section{References}

1. Oil and Hazardous Materials/Technical Assistance Data System (OHM/TADS). Tomes Plos V33: Micromedix Inc; 1997.

2. Patel AS, Talbott EO, Zborowski JV, Rycheck JA, Dell D, Xu X, et al. Risk of cancer as a result of community exposure to gasoline vapor. Arch Environ Health, 2004, 59: 497-503.

3. Weasel CP. Benzene exposure: an overview of monitoring methods and their findings. Chem Biol Interact 2010; 184: 58-66.

4. Kotb MA, Ramadan HS, Shams El-Din R,M Motaweh HA, Shehata RR, El-Bassiouni EA. Changes in some biophysical and biochemical parameters in blood and urine of workers chronically exposed to benzene. Eur Sci J. 2013; 9: 411-422.

5. Egeghy PP, Hauf-Cablo L, Gibson R, Rappoport SM. Benzene and naphthalene in air and breath as indicators of exposure to jet fuel. Occup Environ Med 2003;n 60: 969976. 
6. Kalf GF, Schlosser MJ, Renz JF, Pirozzi SJ. Prevention of benzene-induced myelotoxicity by nonsteroidal anti-inflammatory drugs. Environ Health Perspect 1989; 82: 57-64.

7. Sherwood RJ. Pharmavokinetics of benzene in humans after exposure at about the occupational limit. Ann NY Acad Sci 1988; 534: 635-647.

8. Sherwood RJ, Carter FWG. The measurement of occupational exposure to benzene vapour. Ann Occup Hyg 1970; 13: 125-146.

9. Rothman N, Bechtold WE, Yin SN, Dosimici, M, Wang YZ, et al. Urinary excretion of phenol, catechol, hydroquinone and muconic acid by workers occupationally exposed to benzene. Occup Environ Med 1988; 55: 705-711.

10. Mohamed EI, Khalil GI, Abdel-Mgeed SM, Bayoumi AM, Ramadan HS, Kotb MA. Electronic nose for monitoring benzene occupational exposure in biological samples of Egyptian workers. Int Occup Med Environ Health. 2013; 26: 165-172.

11. Roper D, Layton M, Lewis SM. Investigation of the hereditary hemolytic anemia: membrane and enzyme abnormalities. In: Lewis SM, Bain BJ and Baites editors. Decie and Lewis Practical Haematology; $4^{\text {th }}$ edition. London: Harcourt Publisher Ltd; Chapter 10: 2001, pp 167-198.

12. Olmos V, Lenzken SC, Lopez CM, Villaamil EC. High performance liquid chromatography method for urinary trans, transmuconic acid. Application to environmental exposure to benzene. J Anal Toxicol 2006; 30: 258-261.

13. Ducos P, Gaudin R, Robert A, Francin JM, Maire C. Improvement in HPLC analysis of urinary trans, trans-muconic acid, a promising substitute for phenol in assessment of benzene exposure. Int Arch Occup Environ Health 1990; 62: 529-534.

14. Satoh K. Serum lipid peroxide in cerebrovascular disorders determined by a new colorimetric method. Clin Chim Acta 1978; 90: 37-43.

15. Ohkawa H, Ohishi w, Yagi K. Assay for lipid peroxides in animal tissues by thiobarbitiuric acid reaction. Annal Biochem 1979; 95: 351-358.

16. Richardson RJ, Murphy SD. Effect of glutathione depletion on tissue deposition of methylmercury in rats. Toxicol Appl Pharmacol 1975; 31: 505-519

17. Schafer FQ, Buetner GR. Redox environment of the cell as viewed through the redox state of the glutathione disulphide/glutathione couple. Free Radic Biol Med 30: 11411212, 2001.

18. Savitz DA, Andrews KW. Review of epidemiologic evidence on benzene and lymphatic and hematopoietic cancer. Am J Ind Med 1997; 31: 287-295.

19. Rinsky RA, Young RJ, Smith AB. Leukemia in benzene workers. Am J Ind Med 1981, 2: $217-245$.

20. Aksoy M (1988). Benzene hematotoxicity. In Benzene Carcinogenicity, Chapter 4, Aksoy M (ed.), CRC Press Inc., Boca Raton, Fl., pp 59-112.

21. Cooper K, Snyder R. (1988). Benzene metabolism (toxicokinetics and the molecular aspects of benzene toxicity). In: Benzene Carcinogenicity, Aksoy M (ed.), CRC Press Inc. Boca Raton, Fl., pp 35-58.] 
22. Sato A, Fujiwara Y. Elimination of inhaled benzene and toluene in man. Sangyo Igaku (Jap J Ind Health, 1975; 14: 224-225

23. Rickert DE, Baker TS, Bus JS, Barrow CS, Irons RD. Benzene disposition in the rat after exposure by inhalation. Toxicol Appl Pharmacol 1979; 49: 417-423.

24. Hecker M, Ullrich $\mathrm{V}$. On the mechanism of prostacycline and thromboxane A2 biosynthesis. J Biol Chem 1989; 264: 141150.

25. Esterbauer H, Schaur R, Zollner H. Chemistry and biochemistry of 4-hydroxynonenal, malondialdehyde and related aldehydes. Free Radic Biol Med. 1991; 11: 81-128

26. Voitkun V, Zhitkovich A. Analysis of DNA-protein cross-linking activity of malondialdehyde in vitro. Mutat Res 424: 97-106, 1999.

27. Pastoret A, Federici G, Bertini E, Piemonti F. Analysis of glutathione: Implication in redox and detoxification. Clin Chim Acta 2003; 333: 19-39.

28. Aydin A, Orhan H, Sayal A, Ozata M, Sahin G, Isimir A. Oxitative stress and nitric oxide related parameters in type II diabetes mellitus: effects of glycemic control. Clin Biochem 2001; 34: 65-70.

29. Durkova Z. Some current insights into oxidative stress. Physiol Res 2010; 59: 495-469

30. Khalade A, Jaakkola MS, Pukkala E, Jaakkola JJ. Exposure to benzene at work and the risk of leukemia: a systematic review and meta-analysis. Environ Health 2010; 9: 31-41.

31. Huff J. Benzene-induced cancers: abridged history and occupational health impact. Int J Occup Environ Health 2007; 13: 213-221.

32. Popel AS, Johnson PC. Microcirculation and hemorheology. Ann Rev Fluid Mech 2005; 37: 43-69.

Table (1): Benzene and its metabolites, Phenol and trans, trans muconic acid, in control and benzene-exposed subjects

\begin{tabular}{|c|c|c|c|c|c|c|c|}
\hline \multirow{3}{*}{\multicolumn{2}{|c|}{ Groups }} & \multicolumn{2}{|c|}{ Benzene } & \multicolumn{2}{|c|}{ Phenol } & \multicolumn{2}{|c|}{ t,t,muconic acid } \\
\hline & & \multirow{2}{*}{$\begin{array}{l}\text { Blood } \\
\mathrm{mg} / \mathrm{l}\end{array}$} & \multirow[t]{2}{*}{ Urine } & \multirow{2}{*}{$\begin{array}{c}\text { Blood } \\
\mathrm{mg} / \mathrm{l}\end{array}$} & \multirow{2}{*}{$\begin{array}{c}\text { Urine } \\
\text { mg/g } \\
\text { creatinine }\end{array}$} & \multirow{2}{*}{$\begin{array}{l}\text { Blood } \\
\mathrm{mg} / \mathrm{l}\end{array}$} & \multirow{3}{*}{$\begin{array}{c}\begin{array}{c}\text { Urine } \\
\text { mg/g } \\
\text { creatinine }\end{array} \\
0.07\end{array}$} \\
\hline & & & & & & & \\
\hline \multirow[b]{2}{*}{ Control } & Mean & ND & ND & 1.11 & 1.75 & ND & \\
\hline & SD & ----- & ----- & $\begin{array}{c}+ \\
0.57\end{array}$ & +1.02 & ----- & +0.02 \\
\hline \multirow{2}{*}{$\begin{array}{l}\text { Benzene } \\
\text { exposed } \\
\text { workers }\end{array}$} & Mean & ND & ND & $1.92 *$ & $3.15^{*}$ & 0.97 & $1.16^{*}$ \\
\hline & SD & ----- & ------ & $\begin{array}{c}+ \\
0.72\end{array}$ & +1.31 & $\begin{array}{c}+ \\
0.38\end{array}$ & +0.35 \\
\hline
\end{tabular}

Data presented as mean + standard deviation (SD)

*significantly different from control, $\mathrm{p}<0.05$, ND, not detected

Table (2): Results of oxidative stress and antioxidant defense in control and benzeneexposed subjects

\begin{tabular}{|l|c|l|l|l|l|l|}
\hline Groups & MDA & $\begin{array}{l}\text { Total } \\
\text { antioxidant }\end{array}$ & $\begin{array}{l}\text { Total } \\
\text { glutathione }\end{array}$ & $\begin{array}{l}\text { Reduced } \\
\text { glutathione }\end{array}$ & $\begin{array}{l}\text { Oxidized } \\
\text { glutathione }\end{array}$ & $\begin{array}{l}\text { Redox } \\
\text { potential }\end{array}$ \\
\hline
\end{tabular}




\begin{tabular}{||c|c|c|c|c|c|c||}
\hline & $\mathbf{m m o l} / \mathbf{m l}$ & $\mathbf{m m o l} / \mathbf{L}$ & $\mathbf{m m o l} / \mathbf{L}$ & $\mathbf{m m o l} / \mathbf{L}$ & $\mathbf{m m o l} / \mathbf{L}$ & $\mathbf{~ m V}$ \\
\hline Control & 1.15 & 1.51 & 4.08 & 3.61 & 0.23 & -116.0 \\
& +1.04 & +0.55 & +0.31 & +0.34 & +0.12 & +8.86 \\
\hline Benzene & 1.81 & 0.83 & 3.78 & 3.19 & 0.29 & -108.4 \\
exposed & $+1.11^{*}$ & $+0.55^{*}$ & $+0.46^{*}$ & $+0.38^{*}$ & $+0.07^{*}$ & $+3.51^{*}$ \\
workers & & & & & & \\
\hline
\end{tabular}

Data presented as mean + standard deviation, $\quad \mathrm{MDA}=$ malondialdehyde *significantly different from control, $\mathrm{p}<0.05$ 